\title{
Developing Students' Vocabulary In English Speaking Ability By Using Talk-Show Video As Directed Practice Media
}

\author{
Ichwan Purwata
}

Sekolah Tinggi Manajemen Informatika dan Komputer, Indonesia

Correspondence: Ichwan Purwata, STMIK, Indonesia. E-mail: ichwanpurwata2017@gmail.com

Received: November 21, 2017

Accepted: Desember 21, 2017 Online Published: April 1, 2018

doi: $10.29408 /$ veles.v2i1.504.g425

URL: http://dx.doi.org/10.29408/veles.v2i1.504.g425

\begin{abstract}
This research is aimed to: (1) identify how talk show video as a directed practice media could improve students' vocabulary in speaking ability and (2) describe classroom climate when talk show video as a directed practice media was applied in the speaking class. The method used in this research was classroom action research. The research was conducted in two cycles from September 24th until October 30th at the first semester students of English class in STMIK LOMBOK Praya 2017/2018. The research data were collected by using techniques of qualitative and quantitative data collection which include; observation, questionnaire, journal or diaries, document analysis and test. The qualitative data were analyzed through constant comparative method and the statistic data were analyzed through T-test by calculated the studentse score calculation, mean score of pre-test and post-test. The research findings showed that talk show video in teaching and learning English could improve the students' vocabulary in speaking ability and the classroom climate. Video could stimulate and motivate students' interesting in improving their vocabulary in speaking class. As a result, talk show video is suitable for supporting and developing students' speaking ability. It has an important role in teaching and learning process.
\end{abstract}

Keywords: students' vocabulary, speaking ability, talk-show video

\section{Introduction}

One of the important abilities which plays an important role in foreign language acquisition is speaking ability. Many of the students feel anxious in a speaking class, and some are likely to keep silent. Luoma (2005) found that students attending a speaking class often felt anxious due to pressure from the speaking task which was required. The students should master the basic speaking ability which is related to daily life conversation. They 
should be able to pronounce the words in correctly manner; they also should be able to use the language fluently on the level of professional needs. To encourage the students to communicate well, they should be able to arrange sentences grammatically in order to convey the information more easily. Therefore, it is very important for students to develop their speaking ability.

The problem which was arisen at the first semester students of Technique of Information Program of STMIK LOMBOK Praya in the academic year of 2017/2018 was speaking ability. Based on the preliminary study on October 15th 2017, in Technique of Information class of STMIK LOMBOK Praya, most of the students in the classroom were passive in joining the teaching learning process especially in speaking. It could be appeared by two kinds of problem indicators that are students' competence indicators and classroom climate indicators. From students' competence indicator, I found some indicators dealing with the low of the students' speaking ability. The indicators were; they were difficult to know the meaning of the words (words meaning), they pronounced some English words incorrectly (pronunciation) and they had difficulty in using the words in sentences correctly according to the context (words using). From classroom climate indicators, I found some indicators dealing with a low students' speaking ability; the students made some noise and paid little attention toward lesson, some of them seemingly were not interested in the lesson therefore they did not give full attention to the lecturer, and the students did not have a courage or confidence to use English in teaching learning speaking.

In this research, I decided to apply talk-show in teaching learning process. I had strongly believed that talk-show was one method that can be used to develop students' vocabulary in speaking ability. By recording the talk-show and let the students watch what they have done would reflect themselves, they would encourage themselves to get to know more about their vocabularies that related to the topic presented. Video would stimulate and motivate students' interests in speaking class. I decided to focus only on one component which was held to present individually and spontaneously within limited time.

The indicators of vocabulary were: (1) Words meaning; (2) Pronunciation; and (3) words using.

Chaney in Kayi (2006) defines speaking as the "The process of building and sharing meaning through the use of verbal and nonverbal symbols, in variety context". Thornburry 2005: 127) proposes that there are at least five components of speaking abilities, they are comprehension, grammar, vocabulary, pronunciation and fluency: (1) Comprehension, oral communication certainly requires a subject to respond to speech as well as to initiate it; (2) Grammar, it is needed for students to arrange a correct sentence in conversation. The utility of grammar is also to learn the correct way to gain expertise in a language both in oral and written form; (3) Vocabulary, means the appropriate diction which is used in communication. We cannot communicate effectively or express our ideas both in orally and written form when we do not have the sufficient vocabulary; (4) Pronunciation is the way students produce clearer language when they speak. It deals with the phonological process that refers to the 
component of a grammar made up of the elements and principles that determine how sounds vary the sentence patterns in a language; and (5) Fluency, Fluency can be defined as the ability to speak fluently and accurately. Fluency in speaking is the aim of many language learners.

According to Wang (2012: 476), there are three strategies in teaching speaking: (1) Teachers' questioning strategy. The communicative language teaching theory shows that the communication and interaction in class facilitate the language learning. They are the purpose of the language learning. The teachers talk and make some questions in the class being engaging the language learners thinking about the learning materials. Teachers' questioning strategy aids language learners to make critical thinking in learning process and guide learners to achieve the better understanding of the learning materials. The teachers' questioning strategies included types of questions, wait time and feedback; (2) Students' cooperative learning. Cooperative learning is the successful teaching strategy in which small teams, each with students of different levels of ability, use a variety of learning activities to develop their understanding of a subject. Each member of a team is responsible not only for learning what is taught but also for helping teammates learn, thus creating an atmosphere of achievement; and (3) Free talk-show in the class. A self-confident language learner has a positive attitude to learning. They will find every chance to learn the target language and participate in any language activities. Prepared free talk-show allows the students have a good preparation for the talk-show in class. They rehearsed it with their group members to practice the talk-show that will be given in class next time can build students' self-confidence.

According to Wollacott (2012) there are four main types of vocabulary. They are reading, writing, listening and speaking vocabularies: (1) Reading Vocabulary. A reading vocabulary is a passive one, the person is able to recognize the form of the letters and how they correspond to one another, and how their sum is understandable; (2) Listening Vocabulary. Listening is also a passive type of vocabulary. The listener is able to link the words being spoken to their meaning; and (3) Writing Vocabulary. Writing is the active vocabulary equivalent to reading. With reading, it forms the core abilities needed for someone to literate.

Speaking is an active demonstration that can also rely on other elements such as facial expressions, intonation, pitch and gestures to help others understand its meaning. Knowledge of a word is demonstrated by its good usage and pronunciation.

Talk-show is one of teaching strategies to motivate the students to get involved actively in the teaching learning process. Herrell and Jordan in Dwinesa (2013: 25) define talk-show as a strategy that encourages the production of verbal English based on information and verbalizations studied ahead of time.

According to Herrel and Jordan in Dwinesa(2013), the steps in using talk-show in the classroom are the following: (1) Choose an appropriate topic. The teacher identifies an appropriate topic for talk-shows implementation. The topic must be one where the students can gain information about the person to be interviewed from reading or researching; (2) Explain and model the talk-show strategy. The teacher explains talk-show by referring to a 
television talk-show with the students may be familiar, Oprah for example. The teacher models the role of the talk-show host by having one student come up to be interviewed about a recent classroom event. Before interviewing the students, the teacher asks the rest of the class to brain storm questions for the person to be interviewed. The teacher writes this brainstorming on a chart or chalkboard so all students can see ways to formulate questions for the interview. The teacher then models an interview with the students; (3) Give the group guided practice. The teacher divides the class into groups of three and gives them a topic to practice. Each group selects their interviewer, interviewee, and brainstorms a list of questions. The interviewer must practice asking questions that cannot be answered with one-word responses. The teacher circulates around the room while the students practice their interviews, encouraging groups to think of interesting questions and responses; (4) Presence to the class. After the groups have had an opportunity to practice their interviews, they come up in front of the class and perform for the group. With groups with very limited English, this step may be skipped until the students have had more time and experience with the English or may be limited to the volunteer groups. After each group performs, the teacher identifies especially good questions and responses; (5) Add technology. The group can find visuals on the internet and use a program such as power-point to create a series of visuals to support the class' understanding of the interview. When one of the students is adept at drawing, the group can use the overhead projector so the interpreter can illustrate the interview as its progress. The groups might also videotape the interviews and show the tape instead of performing the interview alive.

Reflective practice is a way of studying our own experiences to develop the way we work. It is very useful for the health professionals who want to carry on learning throughout our lives. Engaging in reflective practice should help to improve the quality of care we give and close the gap between theory and practice. The act of reflection is a great way to increase confidence and become a more proactive and qualified professional. According to Roffey (2009), directed practice is the process of learning through and from experience towards gaining new insights of self and/or practice.

According to Tice (2011), there are four ways in doing reflective practice in the classroom: (1) Teacher diary. This is the easiest way to begin a process of reflection since it is purely personal. After each lesson, teacher writes in a notebook about what happened; (2) Peer observation. Invite a colleague to come into your class to collect information about the lesson. For example, you might ask your colleague to focus on which students contribute most in the lesson, what different patterns of interaction take place or how you deal with errors; (3) Recording lesson. Video or audio recordings of lesson can provide very useful information for reflection. Teacher may do things in class and do not aware of or there may be things happening in the class that as the teacher you do not normally see; and (4) Students feedback. Teacher can also ask her/his students what they think about what goes on in the classroom. This can be done with simple questionnaires or learning diaries for example. 
The Talk Show dramatizes the exploration of literature. In creating a talk show, the students interpret characters, conflicts, themes and issues for live audience on a classroom stage. Rivers in Yulia (2003: 172) mentions several advantages of using video. It is now possible to bring into the classroom a more vivid presentation of the foreign culture than the teacher was able to do with pictures and objects since video combines objects, pictures, actions, and gestures in one package to illustrate meaning.

Through video, students, of course, can also see the gestures and facial expressions which play an essential role in clarifying the part of the meaning which is conveyed by intonation and tone voice. The picture, with accompanying voice, has a greater sensory impact than lines on a printed page or even than that of the voice alone. Video helps the students speak without self-consciousness.

Meyer (2002) in Muniandy and Veloo (2011: 173) defines video as a kind of multimedia material consisting of verbal and non-verbal presentations displaying simultaneous images, narration and on screen text. Furthermore, McKinnon (2011) in Muniandy and Veloo (2011: 175) acknowledges that video clips can portray settings, action, emotions, and gestures which can provide the important visual stimulus for language practice and learning. It means that videos can be used in teaching English because videos can provide great visual stimuli through their combination of illustrations, sounds, graphics, and texts.

Richards and Renandya (2002: 364) add that a video is an extremely dense medium, one which incorporates a wide variety of visual elements and a great range of audio experiences in addition to spoken language. The teacher is there to choose appropriate sequences, prepare the students for the viewing experience, focus to students' attention on the content, play and replay the video as needed, design or select viewing tasks, and follow up with suitable post viewing activities. They also state that a video potential in language learning is only achieved when it is used as an integral part of course. When the teachers decide to use video as supplementary materials, they must believe that it is closely related with the goals of the course. One way to do this is to bring in the video to introduce or to expand a theme of the material that is already part of the curriculum.

Harmer (2001: 282) also says that a video is not only a great aid to see language-in-use such as comprehension since students are able to see general meanings and moods that are conveyed through expression, gestures, and other visual clues, but also uniquely bridge the cross cultural understanding. They will see how typical British 'body language' is when inviting someone out or how Americans speak to waiters. He also mentions that for all of the reasons mentioned, most students show an increased level of interest when they have a chance to see language in use as well as hear it.

\section{Method}

The method employed in this research was Classroom Action Research (CAR). Action research is a systematic process that enables person to find the effective problem solution in their lives (Stringer, 2007:1). Mills (2000: 6) defines action research as any systematic inquiry 
conducted by teacher researchers, principals, school counselors, or other stakeholders in the teaching learning environment, to collect some information about the ways that their particular schools operation, how they teach, and how well their students learn.

This research was done in the form of collaborative action research. In doing a collaborative action research, I was helped by my assistant, a lecture of IT Program of STMIK LOMBOK Praya. This research's participants were the first semester students of English class in STMIK LOMBOK Praya. The procedures of Classroom Action Research was proposed by Kemmis and Taggart model in Burns (1999:35); planning, action, observation, and reflection.

In planning step, firstly, I identified the problem referring to the teaching learning process that would be researched in this study. Secondly, the speaking lecturer as a collaborator and I made a plan about what kind of action would be carried out and prepared everything dealing with the action research requirements, such as (1) designed the talk show activities and recorded into video, (2) decided the objectives that would be achieved in observation form that would be done by me as a researcher, and (3) designed the tests that would be used to know the success of the action.

After the planning, I applied the next action, implementation, in this phase, both speaking lecturer and I collaborated to carry out the planned action. I determined the strategy that was applied in the classroom. I changed the lecturer's position conducting the research, while the lecturer observed the condition and activities in the classroom.

In observation step, the students' activities during the implementation of Talk-Show activities would be recorded by the direct observation. I recorded the important occurrence during the teaching learning process. The last step is reflection. Reflection is a way to see whether the implementation of Talk-Show video activity in presentation is successful or failed to improve students' speaking ability.

\section{Results and discussion}

From the implementation of talk show activities, there was an improvement on students' English vocabulary in speaking ability; the summary of the improvement result can be seen in the following tables:

Table 1. The average scores of speaking components

\begin{tabular}{lll}
\hline No & The Component of Speaking & Average Score \\
\hline 1 & Comprehension & 75.00 \\
2 & Grammar & 70.50 \\
3 & Vocabulary & 77.67 \\
4 & Pronunciation & 70.00 \\
5 & Fluency & 70.42
\end{tabular}


Table 2. The mean score for each vocabulary indicators

\begin{tabular}{llll}
\hline Indicator & Pre-Test & Post-Test 1 & Post-Test 2 \\
\hline Word Meaning & 64.18 & 72.53 & 80.85 \\
Pronunciation & 63.42 & 69.77 & 75.62 \\
Word in Use & 63.59 & 68.85 & 76.55 \\
Students' Average Score & $\mathbf{6 3 . 7 3}$ & $\mathbf{7 0 . 3 8}$ & $\mathbf{7 7 . 6 7}$ \\
\hline
\end{tabular}

Table 3. The improvement of students' class situation

\begin{tabular}{lll}
\hline Pre-Research Condition & After Cycle 1 & After Cycle 2 \\
$\begin{array}{l}\text { Some of the students did not } \\
\text { involve in class activities and } \\
\text { prefer being quiet }\end{array}$ & $\begin{array}{l}\text { Some of the students } \\
\text { involved in talk show during } \\
\text { answer questions session, } \\
\text { and gave comment or } \\
\text { suggestion at the end or talk } \\
\text { show }\end{array}$ & $\begin{array}{l}\text { Some of the students involved } \\
\text { in talk show during answer } \\
\text { questions session, and gave } \\
\text { comment or suggestion at the } \\
\text { end or talk show }\end{array}$ \\
$\begin{array}{l}\text { Some of the students seemed } \\
\text { not interested in the lesson } \\
\text { therefore they did not give } \\
\text { full attention to the lecturer }\end{array}$ & $\begin{array}{l}\text { fairly interested and gave } \\
\text { attention to the lesson. }\end{array}$ & $\begin{array}{l}\text { Some of the students were } \\
\text { fairly interested and gave } \\
\text { attention to the lesson. }\end{array}$ \\
\hline
\end{tabular}

Moreover, they also got some various vocabularies in using the language function. No doubt, they also learned some expressions, facial expression, gesture, and how to ask question depending on the form (formal/informal) and the context needed.

Table 4. The mean score for each vocabulary indicators

\begin{tabular}{llll}
\hline Indicator & Pre-Test & Post-Test 1 & Post-Test 2 \\
\hline Word Meaning & 64.18 & 72.53 & 80.85 \\
Pronunciation & 63.42 & 69.77 & 75.62 \\
Word in Use & 63.59 & 68.85 & 76.55 \\
Students' Average Score & 63.73 & 70.38 & 77.67 \\
\hline
\end{tabular}

From the Table 4, can be seen that the students' each vocabulary indicator such as word meaning, pronunciation, and word in use has increased from cycle to cycle. 
Graph. 1. The Result of the Students' Mean Score

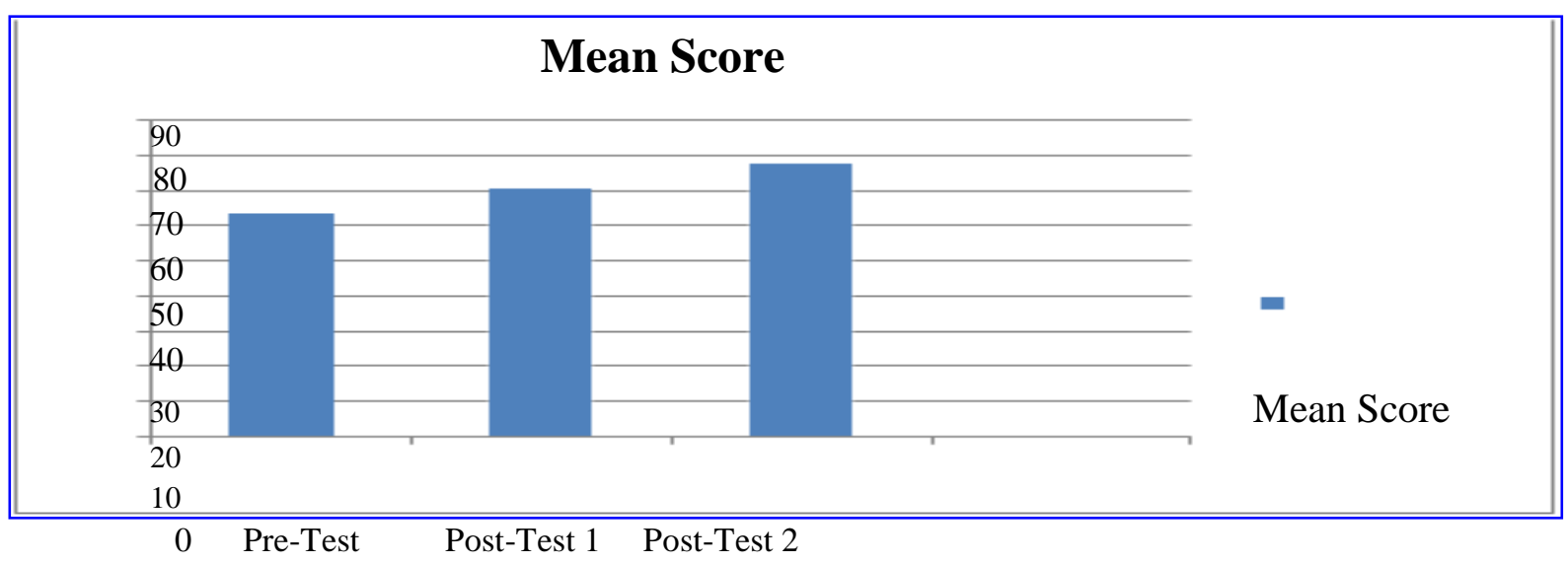

Based on the graph 1, it could be concluded that the students' speaking ability developed. The students' mean score for each cycle was increasing significantly. By considering the fact, there was the good advancement achieved by the students and there were many benefits when talk-show was urgently needed to develop the students' speaking ability at English Class for the first semester students of STMIK LOMBOK Praya. For other English lecturers who want to develop their students' achievement, they may try to implement talk-show in their teaching activities especially speaking class.

In addition, Talk show video had advantages of achieving the important goals such as motivating students' interest, providing realistic listening practice, stimulating language use, and heightening students' awareness of particular language points or other aspects of communication.

According to Alessi (2001: 538), video is a powerful tool for learning and instruction. It is difficult to illustrate human behavior in interpersonal situations, for example, it is hard to show a student the effects of body language on communication using only explanation or pictures. Video here has also been included for motivational reason.

Harmer (2001: 284) states there are many advantages in using videos in the teaching and learning process such as:

1) Seeing language-in-use, students do not just hear language but they can also see it. They can know the general meaning and moods that are conveyed through expressions, gesture, and other visual clues.

2) Cross-cultural awareness, which is allowing students a look at situations for beyond their classroom. Videos also give students a chance to see such things as what kinds of food people eat in other countries and what they wear.

3) The power of creation, when students use video cameras themselves they are given the potential to create something memorable and enjoyable.

4) Motivation, most students show an increased level of interest when they have a chance to see language in use as hear it, and when this is coupled with communicative tasks. 
Smaldino et al (2007: 291) adds that teachers can use video to provide baseline knowledge for all students. It means that video can give some benefits to the students in many fields as follows:

1) Cognitive skills

Students can observe dramatic recreations of historical events and actual recordings of more recent events. Color, sound and motion make personalities come to life.

2) Demonstration

Video is great for showing how things work. If teachers are teaching a step by step process, teachers can show it in real time, sped up to give an overview or slowed down to show specific details.

3) Virtual Field Trips

Video can take students to places they might not be able to go

4) Documentary

Video is the primary medium for documenting actual events and bringing them into classroom.

5) Dramatization

6) Video has the power to hold the students spellbound as a human drama unfolds before their eyes.

7) Discussion Basic

By viewing a video together, a diverse group of students can build a common base of experience as a catalyst for discussion.

From the discussions above, it was clear that videos had many advantages. Videos could support the speaking teaching and learning process. The students could learn language not only by listening how native speakers pronounced some words but also by observing their facial expressions and gestures.

According to the relevant study showing that the use of videos in English teaching and learning process could improve the students' speaking skills. Bagil Safitri (2014) conducted a research in SMAN 1 Mataram on October, 2013, during the first semester of the academic year of 2013/2014. Her research study was successful to improve the students' English speaking skills. The actions which were carried out in two cycles were effective in improving the students' motivation, self-confidence, and some speaking aspects. The use of videos also could give good speaking model for students in using certain expression in certain situation and also help the students in developing their speaking skill in the real world context.

The other relevant study was from Tawatchai et al. (2014). They used videos in the form of video conferencing (Skype) for EFL secondary school students. It is a kind of realworld video. Skype in the classroom is a website on which teachers worldwide can post ideas for Skype lessons, connect with other classrooms and come up with ways to collaborate via Skype (Waxman, 2012). The outcomes of this study indicated that this project 
successfully motivated students, developed the intercultural awareness, and improved oral communication ability.

Therefore, talk show activity could be concluded into three main purposes; (1) they did various activities during teaching learning using talk show video, (2) they could interact with their friends and collaborate with them during teaching learning speaking process, and (3) they could be responsible to their jobs. As a result, talk show video was suitable for supporting and improving students ${ }^{e e}$ speaking skill, it had important role in teaching and learning process.

\section{Conclusion}

There were many effective teaching learning procedures using talk show; (1) they could make the students more interesting in joining the speaking class, (2) the effective teaching learning procedures using talk show could make the optimum speaking ability of the students and speaking class; achieved, interested, alive, and happy.

Based on the precious experiences that the research got during carrying out the research, I would like to recommend some suggestions, as follows: (1) For the English teachers/lecturers. For development of students' speaking ability, The English teachers/lecturers are suggested to: (a) Develop five elements of speaking which covers fluency, grammar, pronunciation, vocabulary and content; (b) Develop their creativity in teaching English, for example by using interesting technique to attract the students' motivation, using aids to present the material, using different techniques in teaching learning process; and (c) Develop their abilities in managing class, in order to create improvement during teaching learning process; (2) The students. For improvement of students' speaking ability, the students are suggested to: (a) Do what the teachers/ lecturers instruct seriously; (b) Practice speaking in English as much as possible to develop the speaking ability; and (c) Join the English clubs which can increase achievement and improve the speaking ability; (3) for the college and other institutions.

To support the effectiveness of teaching and learning process, the college and other institutions are suggested to: (a) Provide enough fund for the sake of the teachers/ lecturers creativity including holding English speech contest and buying media; (b) Facilitate the classroom with modern media like speakers, LCD, and laptop; and (c) Provide the language laboratory; and (4) For other researchers. Other researchers are expected to use the finding of this research as a foothold to conduct the next research on similar problems through other teaching techniques. Other researchers are expected to use the finding of this research as a foothold to conduct the next researches on similar techniques through other language skill such as speaking, writing or listening. This study can be a reference for other researchers to conduct the next research if there are some weaknesses. 


\section{References}

Dwinesa, A. 2013. Improving Vocabulary in Students' English Speaking Skill by Using Talk Show. Surakarta: Sebelas Maret University.

Kayi, H. 2006. Teaching Speaking: Activities to Promote Speaking in a Second Language. The Internet TESL Journal. Vol. XII, no.11, November. Retrieved from http://iteslj.org/techniques/Kayi-Teaching-Speaking.html.

Kemmis, S. R. 2013. The Action Research Planner: Doing Critical Participatory action Reseach. New York: State University of New York Press.

Luoma, S. 2005. Assessing Speaking. Cambridge: University Press.

Roffey, B. J. 2009. Reflective Practice in the lifelong Learning sector. London: Exeter Learning Press.

Stringer, E. T. 2007. Action Research. Sidney: Curtin University of Technology Press.

Thornburry, S. 2005. How to Teach Speaking; Practice and Theory. Cambridge: Cambridge University Press.

Tice, J. 2011. Reflective Teaching: Exploring Our Own Classroom Practice. London: British Council Press.

Wang, Q. 2012. Classroom Teaching Strategies of Improving the English Majors' Selfinstruction in Newly-Promoted University in China. Theory and Practice in Language Studies, 2 no.3, 475-482. 